\title{
Randomized trial comparing episiotomies with Braun-Stadler episiotomy scissors and EPISCISSORS-60 ${ }^{\circledR}$
}

This article was published in the following Dove Press journal:

Medical Devices: Evidence and Research

I June 2015

Number of times this article has been viewed

\section{Ganpat Sawant \\ Divya Kumar}

Dr DY Patil Medical College and Hospital, Nerul, Navi Mumbai, India
Correspondence: Ganpat Sawant Dr DY Patil Medical College and Hospital, Nerul, Navi Mumbai, India Email dypatilrcog@yahoo.com
Introduction: Episiotomy angle is a crucial factor in causation of obstetric anal sphincter injuries (OASIS), which are the major cause of female bowel incontinence. Sutured episiotomies angled too close to the midline ( $<30$ degree) or too far away from the midline ( $>60$ degree) fail to unload the perineum sufficiently and predispose to OASIS. A 25-degree post-delivery episiotomy suture angle has a $10 \%$ risk of OASIS while 45 -degree episiotomy is associated with $0.5 \%$ risk To account for perineal distension at crowning, a 60-degree episiotomy incision is required to achieve 43-50 degree suture angles. We compared episiotomy suture angles with commonly used Braun-Stadler episiotomy scissors with the new fixed angle EPISCISSORS-60 ${ }^{\circledR}$.

Methods: Ethical approval was obtained. A prospective cluster randomization design was chosen. Thirty-one patients were required in each group for a 12-degree difference with power at $90 \%$ and $5 \%$ significance. Sutured episiotomy angles and post-delivery linear distance from caudal end of the sutured episiotomy to the anus were measured with protractors and rulers. Two-tailed $t$-tests were used to compare the two groups.

Results: Thirty-one nulliparae had episiotomies with EPISCISSORS-60 ${ }^{\circledR}, 32$ with Braun-Stadler. Mean age (25 versus 24.8 years) was similar. EPISCISSORS-60 ${ }^{\circledR}$ episiotomies were angled 12 degrees more laterally away from the anus compared to Braun-Stadler (40.6 degrees, 95\% confidence interval $[\mathrm{CI}] \pm 2$, interquartile range [IQR] $35-45$ versus 28.3 degrees, $95 \% \mathrm{CI} \pm 2$, IQR 25-30, $P<0.0001$ ). The post-delivery linear distance from caudal end of the sutured episiotomy to the anus was $15 \mathrm{~mm}$ more with the EPISCISSORS- $60^{\circledR}$ compared to Braun-Stadler ( $35 \mathrm{~mm}, 95 \% \mathrm{CI} \pm 2.2, \mathrm{IQR}=30-39$ versus $19.5 ; 95 \% \mathrm{CI} \pm 1.3, \mathrm{IQR}=14.75-22.25 P<0.0001$ ). EPISCISSORS- $60^{\circledR}$ episiotomies measured longer ( $47 \mathrm{~mm}$ versus $40 \mathrm{~mm}, P<0.0001$ ). There were no OASIS cases in the EPISCISSORS- $60^{\circledR}$ group versus one in the Braun-Stadler group.

Conclusion: The EPISCISSORS- $60^{\circledR}$ sutured episiotomies are much further away from the midline in angular and distance measures, hence at lower OASIS risk.

Keywords: episiotomy, EPISCISSORS-60 ${ }^{\circledR}$, obstetric anal sphincter injuries (OASIS), perineal tears

\section{Introduction}

Obstetric anal sphincter injuries (OASIS) are a major cause of female bowel incontinence which leads to stigmatization in the developing world. Episiotomy angle is a crucial determinant in causation of OASIS. Episiotomies angled too close to the midline or those too far away from the midline fail to unload the perineum sufficiently and predispose to OASIS. ${ }^{1}$ A 25 -degree post-delivery episiotomy suture angle has a $10 \%$ risk of OASIS while 45-degree episiotomy is associated with $0.5 \%$ risk. $^{2} \mathrm{~A} 60$-degree episiotomy incision results in 43-50 degree suture angles. ${ }^{3-5}$ Asian women are believed to be at higher risk for OASIS due to short perineal body length, and the episiotomy 
apex needs to be angled further away from the midline to reduce OASIS risk.

Traditionally, the Braun-Stadler (BS) episiotomy scissors have been used worldwide. The blades are angled to the side by about 15 degrees (Figure 1). The EPISCISSORS-60 ${ }^{\circledR}$ (E60) (Medinvent LLC, Romsey, United Kingdom) are angled-on-flat scissors with a guide-limb that points toward the anus. It is claimed to cut at 60 degrees if the guide-limb is aligned to the anus (Figures 2 and 3).

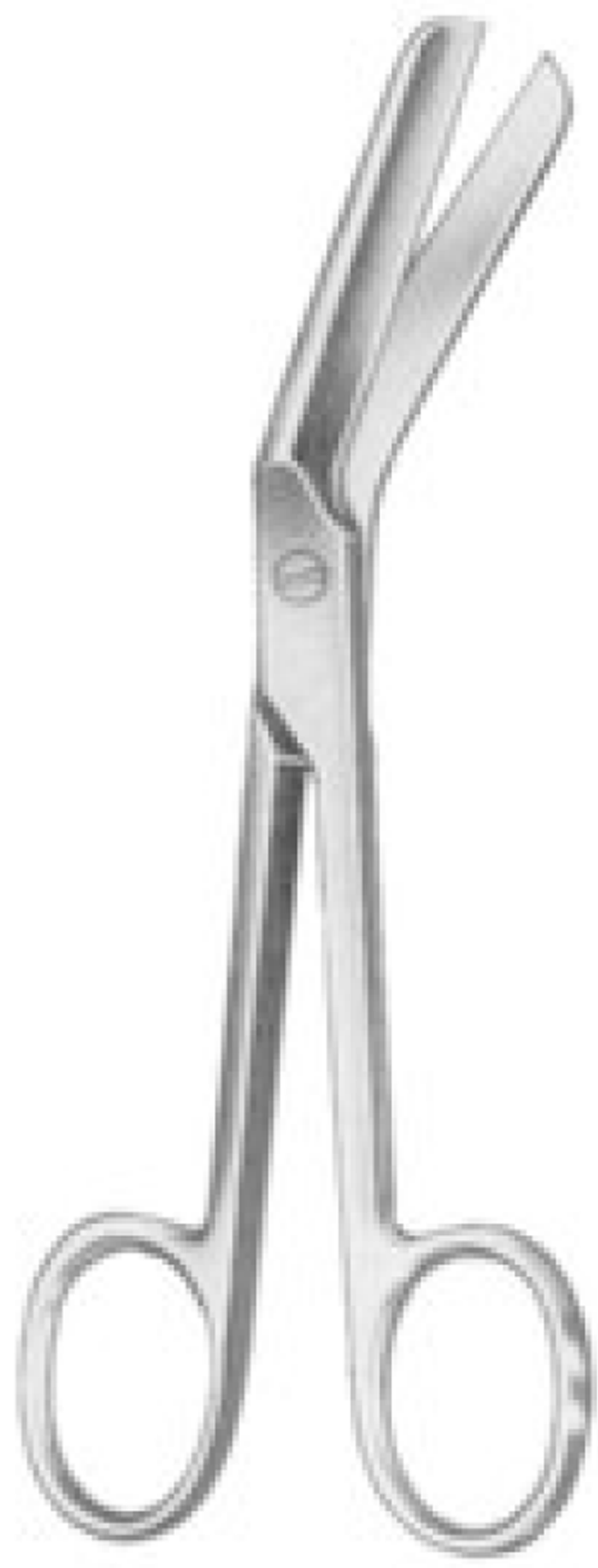

Figure I Braun-Stadler episiotomy scissors.



Figure 2 EPISCISSORS-60 ${ }^{\circledR}$.

We aimed to compare episiotomy suture angles with commonly used BS episiotomy scissors with the new fixed angled E60.

\section{Materials and methods}

Approval was granted by the Institutional Ethics Committee of the Dr DY Patil Medical College Hospital and Research Centre, Nerul, Navi Mumbai for the study. A power calculation showing 11 degrees episiotomy angle difference between the case and controls required 31 women in each

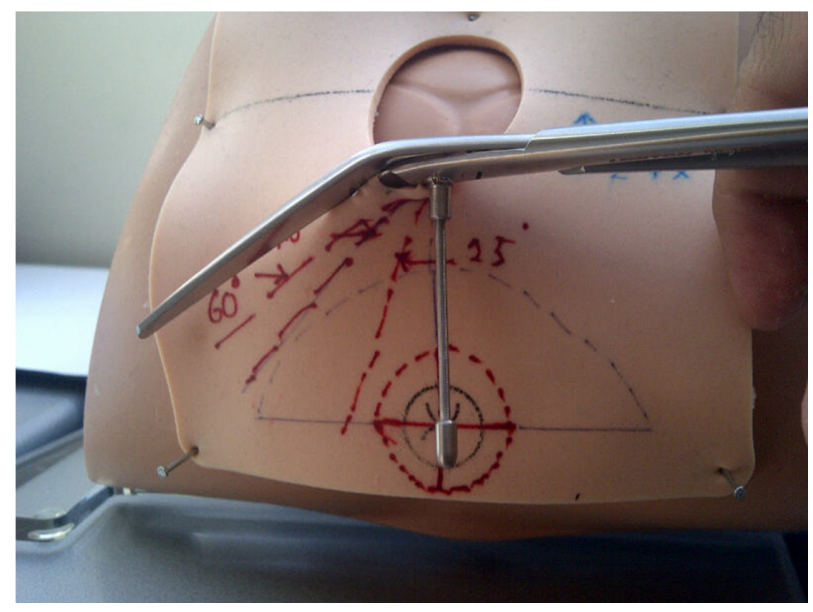

Figure 3 EPISCISSORS- $60^{\circledR}$ in a birth simulation model. 
group with $90 \%$ power and at $5 \%$ significance. This has been used previously by other investigators. ${ }^{6-7}$

Our hospital has two firms which manage the labor ward for 24-hour cycles. Our unit performed episiotomies with the E60, while the other unit continued using the BS scissors. Therefore, our study design was similar to a prospective cluster randomized study design. It has previously been shown that lack of allocation concealment has no importance in studies with objective outcomes. ${ }^{8}$ This design also minimizes the Hawthorne effect of doctors cutting episiotomies more laterally than their usual practice.

Women were recruited from May to October 2014. All women included in the study were nulliparous and underwent episiotomies for common indications such as prolonged second stage of labor, instrumental delivery, and fetal distress. Episiotomies were performed at crowning by doctors. Post-delivery suture angle was measured with a plastic protractor transparency; length of the episiotomy and distance from the caudal end of the episiotomy to the anus were measured with a ruler. All data were entered into a Microsoft Excel sheet. Two-tailed $t$-tests were used to compare the independent groups. Interquartile ranges (IQRs) and confidence intervals (CIs) are reported.

\section{Results}

Results are shown in Table 1. There was a 12-degree difference in the episiotomy angles between the two groups. The EP60 group $(n=31)$ achieved a mean post-delivery suture angle $=40.6$ degrees (range $30-50 ; \mathrm{IQR}=35-45$, standard deviation $[\mathrm{SD}]=5.7,95 \% \mathrm{CI}=38.6-42.6)$, while the BS scissors group $(\mathrm{n}=32)$ achieved a mean angle $=28.3$ degrees (range $20-45, \mathrm{IQR}=25-30, \mathrm{SD}=5.6,95 \% \mathrm{CI}=2 ; 26.3-30.3$ ).
The results are highly statistically significant $(P<0.0001$, two-tailed $t$-test).

The caudal end of the episiotomies was a mean $15 \mathrm{~mm}$ further away from the anus (35 mm versus $19.6 \mathrm{~mm}$, $P<0.0001)$ with the E60.

The length of the episiotomies was $47 \mathrm{~mm}$ in the E60 group compared to $40 \mathrm{~mm}$ in the BS group $(P<0.0001)$.

\section{Discussion}

To the best of our knowledge, this is the first prospective study comparing the E60 with the BS scissors. The mean episiotomy suture angle measured postpartum in our study (40.3 degrees) is similar to that observed by Freeman et al. ${ }^{4}$ It is less than that achieved by Patel and Ubale. ${ }^{5}$ However, $36 \%$ of women in their cohort were parous and this would influence perineal distensibility. This might also be due to an earlier timing of episiotomies by resident doctors in our unit.

Episiotomies with suture angles less than 30 degrees are associated with significantly greater risk of OASIS., ${ }^{2,9}$ It is concerning that the BS scissors resulted in episiotomy angles that are $<30$ degrees.

In comparison, episiotomies with suture angles of 40 degrees are in the safe zone with respect to OASIS, ${ }^{2,9}$ and the E60 achieve these angles.

E60 are fixed angle scissors which will cut at 60 degrees as long as the guide-limb is aligned to the anus. Our results are also similar to El-Din et $\mathrm{al}^{10}$ who found a post-delivery suture angle of 44 degrees with an incision angle of 60 degrees (achieved by marking the perineum with gentian violet).

The anal sphincter complex surrounds the anus in a cylindrical configuration. The closer the caudal end of the

Table I Geometric characteristics of episiotomies with EPISCISSORS-60 ${ }^{\circledR}$ and Braun scissors

\begin{tabular}{|c|c|c|c|}
\hline & $\begin{array}{l}\text { EPISCISSORS-60 }{ }^{\circledR} \\
(\mathbf{N}=3 I)\end{array}$ & $\begin{array}{l}\text { Braun-Stadler } \\
\text { episiotomy scissors }(\mathrm{N}=32)\end{array}$ & \\
\hline Age, years (mean) & 25 & 24.8 & \\
\hline Normal births & 27 & 27 & \\
\hline OVD & 4 & 5 & \\
\hline Mean post-delivery suture angle (degrees) & $40.6(95 \% \mathrm{Cl} \pm 2)$ & $28.3(95 \% \mathrm{Cl} \pm 2)$ & $P<0.000 \mathrm{I} ;$ two-tailed $t$-test \\
\hline IQR & $35-45$ & $25-30$ & \\
\hline SD & 5.7 & 5.6 & \\
\hline RANGE & $30-50$ & $20-45$ & \\
\hline Post-delivery distance from midline $(\mathrm{mm})$ & $35(95 \% \mathrm{Cl} \pm 2.2)$ & $19.6(95 \% \mathrm{Cl} \pm \mathrm{I} .3)$ & $P<0.000$ I; two-tailed $t$-test \\
\hline IQR & $30-39$ & $14.75-22.25$ & \\
\hline SD & 6.26 & 6.6 & \\
\hline Length of episiotomy (mm) & $47.2(95 \% \mathrm{Cl} \pm 3.5)$ & $40(95 \% \mathrm{Cl} \pm \mathrm{I} .9)$ & $P<0.000$ I; two-tailed $t$-test \\
\hline OASIS & 0 & I (Grade 3) & \\
\hline
\end{tabular}

Abbreviations: OVD, operative vaginal delivery; IQR, interquartile range; SD, standard deviation; Cl, confidence interval; OASIS, obstetric anal sphincter injuries. 
episiotomy is to the anus, the more chances of damage to the anal sphincter complex. The distance from the caudal end of the episiotomy to the anus therefore reflects the safety margin. Episiotomies $>15 \mathrm{~mm}$ away from the anus have been shown to have an $87 \%$ reduced risk of OASIS. ${ }^{6}$ E60 resulted in episiotomies that were $35 \mathrm{~mm}$ away from the anus, which is $15 \mathrm{~mm}$ greater than that with the BS scissors.

The E60 resulted in significantly longer episiotomies (47 $\mathrm{mm}$ versus $40 \mathrm{~mm}$ ). It is interesting to note the difference in lengths obtained as both episiotomy scissors have standard $50 \mathrm{~mm}$ long blades. van Dillen et al ${ }^{11}$ reported $39 \mathrm{~mm}$ episiotomy length in their case series of 420 women. However, the type of scissors was not specified. Stedenfeldt et $\mathrm{al}^{7}$ found episiotomies $>17 \mathrm{~mm}$ length have lower incidence of OASIS. The risk reduces by $75 \%$ for every $5.5 \mathrm{~mm}$ increase in length of episiotomy. It is also known that episiotomies that are inadequate in length can undergo medial extensions and inadvertently damage the anal sphincters.

There was one OASIS in the control group. A limitation of this study is that since the study was not powered to detect differences in OASIS, no inferences can be made on this outcome measure. A strength is that it is adequately powered to detect clinically significant differences in episiotomy angles.

E60 provided consistent 60-degree incision angles for episiotomies, which resulted in safer suture angles. Adequately powered randomized trials or time-series analysis are needed to test for reduction in OASIS.

\section{Disclosure}

The authors have no conflicts of interest to disclose.

\section{References}

1. Tincello DG, Williams A, Fowler GE, Adams EJ, Richmond DH, Alfirevic Z. Differences in episiotomy technique between midwives and doctors. BJOG. 2003;110(12):1041-1044.

2. Eogan M, Daly L, O'Connell PR, O'Herlihy C. Does the angle of episiotomy affect the incidence of anal sphincter injury? BJOG. 2006; 113(2):190-194.

3. Kalis V, Landsmanova J, Bednarova B, Karbanova J, Laine K, Rokyta Z. Evaluation of the incision angle of mediolateral episiotomy at 60 degrees. Int J Gynecol Obstet. 2011;112(3):220-224.

4. Freeman RM, Hollands HJ, Barron LF, Kapoor DS. Cutting a Mediolateral Episiotomy at the Correct Angle: Evaluation of a new device: The Episcissors-60. Med Devices (Auckl). 2014;7:23-28.

5. Patel RP, Ubale SM. Evaluation of the angled EPISCISSORS- $60^{\circledR}$ episiotomy scissors in spontaneous vaginal deliveries: A case series. Med Devices (Auckl). 2014;7:253-256.

6. Gonzalez-Diaz E, Moreno Cea L, Fernandez Corona A. Trigonometric characteristics of episiotomy and risks for obstetric anal sphincter injuries in operative vaginal delivery. Int Urogynecol J. 2015;26(2): 235-242.

7. Stedenfeldt M, Pirhonen J, Blix E, Wilsqaard T, Vonen B, Qian P. Episiotomy characteristics and risks for obstetric anal sphincter injury: a case-control study. BJOG. 2012;119(6):724-730.

8. Wood L, Egger M, Gluud LL, et al. Empirical evidence of bias in treatment effect estimates in controlled trials with different interventions and outcomes: meta-epidemiological study. BMJ. 2008;336(7644): 601-605.

9. Andrews V, Sultan AH, Thakar R, Jones PW. Occult anal sphincter injuries - myth or reality? BJOG. 2006;113(2):195-200.

10. El-Din AS, Kamal MM, Amin MA. Comparison between two incision angles of mediolateral episiotomy in primiparous women: a randomised controlled trial. J Obstet Gynaecol Res. 2014;40(7):1877-1882.

11. van Dillen J, Spaans M, van Keijsteren W, et al. A prospective multicenter audit of labour room episiotomy and anal sphincter injury assessment in the Netherlands. Int J Gynaecol Obstet. 2010;108(2): 97-100.
Medical Devices: Evidence and Research

\section{Publish your work in this journal}

Medical Devices: Evidence and Research is an international, peerreviewed, open access journal that focuses on the evidence, technology, research, and expert opinion supporting the use and application of medical devices in the diagnosis, treatment and management of clinical conditions and physiological processes. The identification of novel

\section{Dovepress}

devices and optimal use of existing devices which will lead to improved clinical outcomes and more effective patient management and safety is a key feature. The manuscript management system is completely online and includes a quick and fair peer-review system. Visit http://www. dovepress.com/testimonials.php to read real quotes from authors. 